\title{
Estimates of Critical Power and Anaerobic Work Capacity from a Single, All-Out Test of Less than 3-Min
}

\author{
Bergstrom HC ${ }^{1 *}$, Housh TJ1, Zuniga JM², Camic $\mathrm{CL}^{3}$, Traylor DA ${ }^{1}$, Lewis RW ${ }^{1}$, Schmidt RJ1 and Johnson GO ${ }^{1}$ \\ ${ }^{1}$ Department of Nutrition and Health Sciences, University of Nebraska-Lincoln, USA \\ ${ }^{2}$ School of Allied Health, Western New Mexico University, USA \\ ${ }^{3}$ Department of Health \& Physical Education, University of Wisconsin-Platteville, USA
}

\begin{abstract}
The purpose of this study was to determine if Critical Power (CP) and Anaerobic Work Capacity (AWC) could be estimated from a single, all-out test of less than 3 -min. Twenty-eight subjects (mean \pm SD: age $23.3 \pm 3.3$ years, body mass $71.6 \pm 16 \mathrm{~kg}$ ) performed an incremental cycle ergometer test to exhaustion to determine peak oxygen consumption rate and heart rate peak. The 3-min all-out test was used to determine the criterion and six estimated values of $\mathrm{CP}$ and $\mathrm{AWC}$. The criterion critical power $\left(\mathrm{CP}_{180}\right)$ and anaerobic work capacity $\left(\mathrm{AWC}_{180}\right)$ values were determined from the 3-min all-out test and were expressed as 30-s averages (155-180-s). The six estimated CP and AWC values were calculated from 30 -s averages at decreasing 10-s intervals from 145 to $170-s\left(C P_{170}\right.$ and $A W C$ 135 to 160 -s $\left(\mathrm{CP}_{160}\right.$ and $\left.\mathrm{AWC}_{160}\right), 125$ to $150-\mathrm{s}\left(\mathrm{CP}_{150}\right.$ and $\left.\mathrm{AWC}_{150}\right), 115$ to $140-\mathrm{s}\left(\mathrm{CP}_{140}\right.$ and $\left.\mathrm{AWC} \mathrm{CW0}_{140}\right), 105$ to $130-\mathrm{s}$ $\left(\mathrm{CP}_{130}\right.$ and $\left.A W C_{130}\right)$, and 95 to $120-\mathrm{s}\left(\mathrm{CP}_{120}\right.$ and $\left.A W C_{120}\right)$. Mean differences, total error, constant error, standard error of the estimate, and correlations were used to compare the criterion to the estimated CP and AWC values. The results of the present study indicated that 150-s was the shortest test duration that resulted in non-significant differences between the criterion $\left(\mathrm{CP}_{180}\right.$ and $\left.\mathrm{AWC}_{180}\right)$ and estimated $\mathrm{CP}\left(\mathrm{CP}_{150}\right)$ and $\mathrm{AWC}\left(\mathrm{AWC}{ }_{150}\right)$ values. The subsequent validation analyses showed that there were close agreements for the estimated $C_{150}$ and $A_{W} C_{150}$ versus the criterion $\left(\mathrm{CP}_{180}\right.$ and $\left.\mathrm{AWC}_{180}\right)$ values. Therefore, the current findings indicated that estimates of CP and AWC were not affected by shortening the test by 30 -s. Reducing the length of the test to 2.5 minutes provides a less strenuous, yet valid protocol for estimating $\mathrm{CP}$ and AWC.
\end{abstract}

Keywords: Critical Power (CP); Anaerobic Work Capacity (AWC); All-out test

\section{Introduction}

The Critical Power (CP) test provides estimates of two parameters: $\mathrm{CP}$ and Anaerobic Work Capacity (AWC). Theoretically, CP represents the highest sustainable power output, while AWC is a measure of the total work that can be performed utilizing only stored energy sources within the muscle including Adenosine Triphosphate (ATP), phosphocreatine, glycogen, and the oxygen bound to myoglobin [1-3]. Critical power and AWC have been used to examine the effectiveness of exercise training programs [2,4-6], predict endurance exercise performance [5,7-9], examine the mechanisms of fatigue [4,10,11], describe the effects of prior exercise on performance [12,13], assess the exercise capacity of patients with COPD (chronic obstructive pulmonary disease) [14], determine the efficacy of nutritional supplements [15-19], examine fatigue thresholds $[2,3,6,9,20,21]$, and demarcate the heavy from severe exercise intensity domains $[9,21]$.

The original model of Moritani et al. [2] required three or four exhaustive workbouts on a cycle ergometer to estimate CP and AWC. One objective of exercise testing is to minimize the stress on the subject, while obtaining valid results [22]. Therefore, to improve its practicality, previous studies $[10,21]$ have examined and modified the original CP test of Moritani et al. [2]. For example, Housh et al. [10] reported that instead of three or four workbouts, only two exhaustive workbouts were needed to accurately estimate CP and AWC. Recently, Vanhatalo et al. [21] showed that the 3-min all-out test, proposed by Burnley et al. [12], could be used to estimate CP and AWC. The protocol of Vanhatalo et al. [21], however, requires the measurement and analysis of expired gas samples during an incremental test to exhaustion on an electronically braked cycle ergometer, to determine the power output used for the 3 -min all-out test [12,21]. Therefore, Bergstrom et al. [23] proposed that $\mathrm{CP}$ and AWC could be estimated from the 3-min all-out test and a single workbout by setting the resistance according to the subject's body weight. While both of the 3-min all-out tests of Vanhatalo et al. [21] and Bergstrom et al. [23] reduced the amount of time required to estimate CP and AWC, the demanding nature of an all-out test of 3-min duration may affect the motivation of the subjects to provide a maximal effort throughout the test and limit its application depending on the fitness level of the subjects.

Previous studies have suggested that it may be possible to estimate $\mathrm{CP}$ and AWC from an all-out test that is shorter than 3-min. For example, it has been suggested [24] that anaerobic work capacity reaches its maximum value within 2 min of all-out exercise. In addition, Burnley et al. [12] indicated that the power output at 2-min was not significantly different from the power output at the end of the 3-min all-out test. Thus, if the length of the test could be reduced, it would provide a less strenuous protocol to estimate CP and AWC. Therefore, the purpose of this study was to determine if accurate estimates of $\mathrm{CP}$ and AWC could be obtained from an all-out test of less than 3-min. Based on previous studies [12,24], we hypothesized that the all-out test could be shortened to 2-min without affecting the CP or AWC.

\section{Methods}

\section{Subjects}

Twenty-eight subjects (14 male and 14 female, mean \pm SD: age

*Corresponding author: Haley C Bergstrom, M.S., Department of Nutrition and Health Sciences, 110 Ruth Leverton Hall, University of Nebraska-Lincoln, Lincoln, NE 68583-0806, USA, Tel: (402) 472-2690; Fax: (402) 472-0522; E-mail hbergstrom@unlserve.unl.edu

Received March 23, 2012; Accepted April 21, 2012; Published April 25, 2012

Citation: Bergstrom HC, Housh TJ, Zuniga JM, Camic CL, Traylor DA, et al. (2012) Estimates of Critical Power and Anaerobic Work Capacity from a Single, All-Out Test of Less than 3-Min. J Sports Med Doping Stud 2:107. doi:10.4172/2161. 0673.1000107

Copyright: ( 2012 Bergstrom HC, et al. This is an open-access article distributed under the terms of the Creative Commons Attribution License, which permits unrestricted use, distribution, and reproduction in any medium, provided the original author and source are credited. 
$23.3 \pm 3.3$ years, body mass $71.6 \pm 16 \mathrm{~kg}$, height $175.3 \pm 10.2 \mathrm{~cm})$ volunteered for this study. The subjects were moderately trained [22], and none were competitive cyclists. According to the American College of Sports Medicine [22], moderate training includes aerobic activity performed for a minimum of $30 \mathrm{~min}$ five times a week. Specifically, the subject's physical activities included running $(\mathrm{n}=20)$, cycling $(\mathrm{n}$ $=14)$, and recreational sports $(\mathrm{n}=6)$. This study was approved by the University Institutional Review Board for Human Subjects and all subjects completed a health history questionnaire and signed a written informed consent document before testing.

\section{Procedures}

Determination of $\dot{V} O_{2}$ peak and gas exchange threshold: Each participant performed an incremental test to exhaustion on a calibrated Lode (Corval V3, Groningen, the Netherlands) electronically-braked cycle ergometer at a pedal cadence of $70 \mathrm{rev} \cdot \mathrm{min}^{-1}$. The ergometer seat height was adjusted so that the subject's legs were near full extension at the bottom of the pedal revolution. Toe clips were used to maintain pedal contact throughout the test. All participants wore a nose clip and breathed through a 2-way valve (Hans Rudolph 2700 breathing valve, Kansas City, MO, USA). Expired gas samples were collected and analyzed using a calibrated TrueMax 2400 metabolic cart (Parvo Medics, Sandy, UT, USA). The gas analyzers were calibrated with room air and gases of known concentration prior to all testing sessions. The $\mathrm{O}_{2}, \mathrm{CO}_{2}$, and ventilatory parameters were expressed as 30-s averages [25]. The participants were fitted with a Polar Heart Watch system to record heart rate (Polar Electro Inc., Lake Success, NY). The test began at $50 \mathrm{~W}$ and the power output was increased by $30 \mathrm{~W}$ every 2 min until voluntary exhaustion or the subject's pedal rate fell below $70 \mathrm{rev} \cdot \mathrm{min}^{-1}$ for more than 10 seconds, despite strong verbal encouragement. The $\dot{\mathrm{VO}} 2$ peak was defined as the highest $\mathrm{VO}_{2}$ value in the last $30 \mathrm{~s}$ of the test that met two of the following three criteria [25]: 1) $90 \%$ of agepredicted maximum heart rate; 2) respiratory exchange ratio $>1.1$; and 3) a plateau of oxygen uptake (less than $150 \mathrm{~mL} \cdot \mathrm{min}^{-1}$ in $\mathrm{VO}_{2}$ over the last $30 \mathrm{~s}$ of the test).

The Gas Exchange Threshold (GET) was determined using the V-slope method described by Beaver et al. [26]. The GET was defined as the $\dot{\mathrm{VO}}_{2}$ value corresponding to the intersection of two linear regression lines derived separately from the data points below and above the breakpoint in the $\dot{\mathrm{V}} \mathrm{CO}_{2}$ versus $\dot{\mathrm{VO}}_{2}$ relationship.

Critical power 3-min all-out test: Critical power was determined on the calibrated Lode electronically-braked cycle ergometer, using the procedures of Vanhatalo et al. [21]. To be consistent with the terminology of Moritani et al. [2], the term CP was used to represent the End Power (EP) and AWC was used to represent work done above end power (WEP) as described by Vanhatalo et al. [21]. Each subject completed a warm-up at $50 \mathrm{~W}$ for 5 -min followed by $5 \mathrm{~min}$ of rest. The test began with unloaded cycling at $90 \mathrm{rev} \cdot \mathrm{min}^{-1}$ for $3 \mathrm{~min}$ followed by a 3 min all-out effort at the determined resistance. The participants were instructed to increase the pedaling cadence to $110 \mathrm{rev} \cdot \mathrm{min}^{-1}$ in the last $5 \mathrm{~s}$ of the unloaded phase and then maintain the cadence as high as possible throughout the $3 \mathrm{~min}$ test. The resistance for the test was set using the linear mode of the electronically-braked cycle ergometer (linear factor $=$ power $/$ cadence $\left.^{2}\right)$. The linear factor was calculated as the power output halfway between $\mathrm{VO}_{2}$ peak and GET $(\mathrm{GET}+50 \% \Delta)$ divided by a cadence of $70 \mathrm{rev} \cdot \mathrm{min}^{-1}$ squared $[12,21]$. Thus, the linear factor was equal to GET $+50 \% \Delta /\left(70 \mathrm{rev} \cdot \mathrm{min}^{-1}\right)^{2}$. To prevent pacing and ensure an all out effort, the participants were not made aware of the elapsed time and strong verbal encouragement was provided. The criterion measure of $\mathrm{CP}\left(\mathrm{CP}_{180}\right)$ was the average power output over the final 30-s (155-s to 180-s) of the test and the criterion measure of AWC $\left(\mathrm{AWC}_{180}\right)$ was calculated as the integral of the power versus time relationship above $\mathrm{CP}$ [21]. Six estimated values of $\mathrm{CP}\left(\mathrm{CP}_{170^{2}}\right.$, $\left.\mathrm{CP}_{160}, \mathrm{CP}_{150}, \mathrm{CP}_{140}, \mathrm{CP}_{130}, \mathrm{CP}_{120}\right)$ and $\mathrm{AWC}\left(\mathrm{AWC}_{170}, \mathrm{AWC}_{160}, \mathrm{AWC}_{150}\right.$, $\mathrm{AWC}_{140}, \mathrm{AWC}_{130}, \mathrm{AWC}_{120}$ ) were also calculated from 30-s averages at decreasing 10-s time intervals from 170 -s to 120 -s (i.e., the estimates were calculated from 30 -s averages from 145 to 170 -s, 135 to 160 -s, 125 to 150 -s, 115 to 140 -s, 105 to 130 -s, and 95 to 120 -s).

Statistical analyses: Mean differences among the criterion and estimated CP and AWC values were compared with separate oneway repeated measures ANOVAs at an alpha of $p<0.05$. Post-hoc comparisons were performed using paired $t$-tests at a Bonferroni corrected alpha of $p<0.0071(0.05 / 7)$ (Table 1). Separate zero-order correlation matrices were used to determine the relationships among the criterion and estimated CP and AWC values (Tables 2 and 3). Further validation analyses were based on the evaluation of the criterion versus estimated $\mathrm{CP}$ and AWC via calculations of the total error $\left(\mathrm{TE}=\sqrt{\sum[\text { criterion-estimated }]^{2} / n}\right)$, constant error $(\mathrm{CE}=$ criterion - estimated), standard error of the estimate (SEE (Standard Error of the Estimate) $=\mathrm{SD} \sqrt{1-r^{2}}$ ), correlations between $\mathrm{CE}$ and criterion values, and the similarity between the standard deviations of the criterion and estimated values (Table 4). In addition, the data have been presented using the method of Bland and Altman [27] The analyses were conducted using Statistical Package for the Social Sciences software (v.19.0. SPSS Inc., Chicago, Illinois, USA).

The following criteria were used in the present study to evaluate the results of the validation analyses: (a) the mean values for the criterion $\mathrm{CP}$ and AWC should not be significantly different from the estimated values; (b) there should be close similarity between the TE and SEE; (c) there should be no significant correlation between the CE and the criterion measures; (d) there should be a high correlation between the criterion and estimated values; (e) there should be close agreement between the standard deviation values of the criterion and estimated values.

\section{Results}

The mean $( \pm \mathrm{SD}) \mathrm{VO}_{2}$ peak for the subjects in this study was 42.2 $\pm 7.1 \mathrm{~mL} \cdot \mathrm{kg}^{-1} \cdot \mathrm{min}^{-1}$ and the maximal power output for the incremental test to exhaustion was $231 \pm 51 \mathrm{~W}$. In addition, the GET $(27.7 \pm 5.2$ $\left.\mathrm{mL} \cdot \mathrm{kg}^{-1} \cdot \mathrm{min}^{-1}\right)$ occurred at $66 \%$ of $\mathrm{VO}_{2}$ peak and $60 \%$ of maximal power output $(139 \pm 37 \mathrm{~W})$.

A one-way repeated measures ANOVA indicated that there were no significant differences among $\mathrm{CP}_{180}(187 \pm 47 \mathrm{~W}), \mathrm{CP}_{170}(189 \pm 49$ $\mathrm{W}), \mathrm{CP}_{160}(191 \pm 50 \mathrm{~W}), \mathrm{CP}_{150}(192 \pm 51 \mathrm{~W})$, and $\mathrm{CP}_{140}(193 \pm 51 \mathrm{~W})$ (Table 1). In addition, no significant differences were found among $\mathrm{AWC}_{180}(10.2 \pm 3.4 \mathrm{~kJ}), \mathrm{AWC}_{170}(9.9 \pm 3.5 \mathrm{~kJ}), \mathrm{AWC}_{160}(9.7 \pm 3.4 \mathrm{~kJ})$, and $\mathrm{AWC}_{150}(9.5 \pm 3.3 \mathrm{~kJ})$ (Table 1). Thus, 150-s was the shortest test duration that resulted in non-significant differences between both the criterion $\left(\mathrm{CP}_{180}\right.$ and $\left.\mathrm{AWC}_{180}\right)$ and estimated $\mathrm{CP}\left(\mathrm{CP}_{150}\right)$ and $\mathrm{AWC}$ $\left(\mathrm{AWC}_{150}\right)$ values (Figure 1). Therefore, the subsequent validation analyses were performed between the estimated $\mathrm{CP}_{150}$ and $\mathrm{AWC}_{150}$ values versus the criterion values $\left(\mathrm{CP}_{180}\right.$ and $\left.\mathrm{AWC}_{180}\right)$ (Table 4). The SEE and TE values for CP were $9 \mathrm{~W}$ and $10 \mathrm{~W}$, respectively. The SEE and TE values for AWC were $1.2 \mathrm{~kJ}$ and $1.4 \mathrm{~kJ}$, respectively. The TE represented $5.5 \%$ and $13.7 \%$ of the mean values for the $\mathrm{CP}_{180}$ and $\mathrm{AWC}_{180}$ values, respectively. In addition, there were non-significant ( $\mathrm{p}>0.05$ ) correlations for the $\mathrm{CE}$ versus $\mathrm{CP}_{180}(\mathrm{r}=-0.24)$ and the $\mathrm{CE}$ versus $\mathrm{AWC}_{180}(\mathrm{r}=0.27)$ (Figures 2 and 3 ). The $\mathrm{CP}_{180}$ was highly 
Citation: Bergstrom HC, Housh TJ, Zuniga JM, Camic CL, Traylor DA, et al. (2012) Estimates of Critical Power and Anaerobic Work Capacity from a Single, All-Out Test of Less than 3-Min. J Sports Med Doping Stud 2:107. doi:10.4172/2161-0673.1000107

Page 3 of 5

\begin{tabular}{|c|c|c|c|c|c|c|c|}
\hline Time (s) & 180 & 170 & 160 & 150 & 140 & 130 & 120 \\
\hline $\mathrm{CP}(\mathrm{W})$ & $187 \pm 47$ & $189 \pm 49$ & $191 \pm 50$ & $192 \pm 51$ & $193 \pm 51$ & $196 \pm 52^{*}$ & $199 \pm 54^{*}$ \\
\hline AWC (kJ) & $10.2 \pm 3.4$ & $9.9 \pm 3.5$ & $9.7 \pm 3.4$ & $9.5 \pm 3.3$ & $9.3 \pm 3.1^{\dagger}$ & $9.0 \pm 3.0^{\dagger}$ & $8.8 \pm 3.1^{\dagger}$ \\
\hline
\end{tabular}

significantly different from $\mathrm{CP}_{180}$ at a Bonferroni corrected alpha of $p<0.0071(0.05 / 7)$

${ }^{\dagger}$ significantly different from $\mathrm{AWC}_{180}$ at a Bonferroni corrected alpha of $p<0.0071(0.05 / 7)$

Table 1: Mean ( \pm SD) values for six estimated (170-s, 160-s, 150-s, 140-s, 130-s, and 120-s) and criterion (180-s) measures of Critical Power (CP) and Anaerobic Work Capacity (AWC).

\begin{tabular}{lllllll}
\hline & $\mathrm{CP}_{180}$ & $\mathrm{CP}_{170}$ & $\mathrm{CP}_{160}$ & $\mathrm{CP}_{150}$ & $\mathrm{CP}_{140}$ & $\mathrm{CP}_{130}$ \\
$\mathrm{CP}_{180}$ & 1.00 & & & & \\
$\mathrm{CP}_{170}$ & 1.00 & 1.00 & 1.00 & 1.00 & & \\
$\mathrm{CP}_{160}$ & 0.99 & 0.99 & 1.00 & 1.00 & 1.00 & 1.00 \\
$\mathrm{CP}_{150}$ & 0.98 & 0.98 & 0.99 & 0.98 & 0.99 & 1.00 \\
$\mathrm{CP}_{140}$ & 0.98 & 0.97 & 0.98 & 0.97 & 1.00 \\
$\mathrm{CP}_{130}$ & 0.97 & 0.96 & 0.97 & 1.00 \\
$\mathrm{CP}_{120}$ & 0.96 & $\mathrm{C}$ & & \\
\hline
\end{tabular}

Table 2: Correlation matrix for Critical Power $(\mathrm{CP})$ among the estimated $\left(\mathrm{CP}_{170}, \mathrm{CP}_{160}, \mathrm{CP}_{150}, \mathrm{CP}_{140}, \mathrm{CP}_{130}, \mathrm{CP}_{120}\right)$ and criterion $\left(\mathrm{CP}_{180}\right)$ values.

\begin{tabular}{|c|c|c|c|c|c|c|c|}
\hline & $\mathrm{AWC}_{180}$ & $\mathrm{AWC}_{170}$ & $\mathrm{AWC}_{160}$ & $\mathrm{AWC}_{150}$ & $\mathrm{AWC}_{140}$ & $\mathrm{AWC}_{130}$ & $\mathrm{AWC}_{120}$ \\
\hline $\mathrm{AWC}_{180}$ & 1.00 & & & & & & \\
\hline$A W C_{170}$ & 0.98 & 1.00 & & & & & \\
\hline $\mathrm{AWC}_{160}$ & 0.96 & 0.99 & 1.00 & & & & \\
\hline $\mathrm{AWC}_{150}$ & 0.93 & 0.97 & 0.99 & 1.00 & & & \\
\hline $\mathrm{AWC}_{140}$ & 0.91 & 0.93 & 0.97 & 0.98 & 1.00 & & \\
\hline $\mathrm{AWC}_{130}$ & 0.88 & 0.89 & 0.93 & 0.94 & 0.98 & 1.00 & \\
\hline $\mathrm{AWC}_{120}$ & 0.79 & 0.81 & 0.84 & 0.86 & 0.92 & 0.96 & 1.00 \\
\hline
\end{tabular}

Table 3: Correlation matrix for Anaerobic Work Capacity (AWC) among the estimated $\left(\mathrm{AWC}_{170}, \mathrm{AWC}_{160}, \mathrm{AWC}_{150}, \mathrm{AWC}_{140}, \mathrm{AWC}_{130}\right.$, and $\left.\mathrm{AWC} \mathrm{W}_{120}\right)$ and criterion $\left(\mathrm{AWC}_{180}\right)$ values.

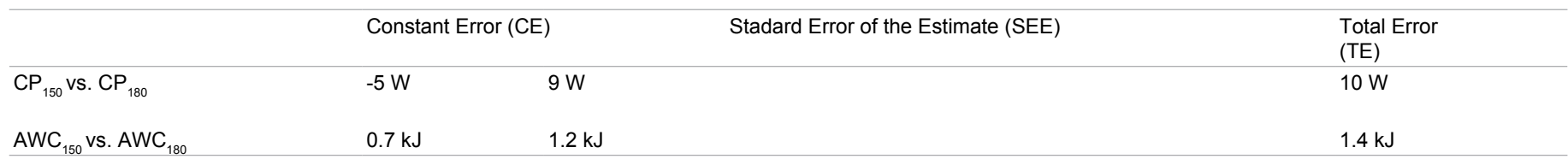

Table 4: Validation analyses $(n=28)$ for the estimated critical power $\left(C_{150}\right)$ and anaerobic work capacity $\left(A_{W} C_{150}\right)$ values versus the criterion $C P_{180}$ and $A W C_{180}$.

correlated with the estimated $\mathrm{CP}_{150}(\mathrm{r}=0.98)$ (Table 2). There was also a high correlation $(\mathrm{r}=0.93)$ between $\mathrm{AWC}_{180}$ and the estimated $\mathrm{AWC}_{150}$ (Table 3). Furthermore, the standard deviations for the $\mathrm{CP}_{180}(47 \mathrm{~W})$ and $\mathrm{AWC}_{180}(3.4 \mathrm{~kJ})$ values were similar to those of the estimated $\mathrm{CP}_{150}$ $(51 \mathrm{~W})$ and $\mathrm{AWC}_{150}(3.3 \mathrm{~kJ})$ values.

\section{Discussion}

The results of the present study, as well as those of previous studies $[12,24]$, suggested that it is possible to estimate CP and AWC from a single, all-out workbout of less than 3 minutes duration. For example, Burnley et al. [12] indicated that there was no significant change in power output over the last minute of the 3-min test (120 to 180-s) and suggested that it may be possible to estimate $\mathrm{CP}$ from a shorter test. During the 3-min all-out test, Burnley et al. [12] found that the power output at 120 -s was only $5 \mathrm{~W}(2 \%)$ greater than the power output at 180 -s. Furthermore, when 30-s averages were considered, Burnley et al. [12] reported that average power outputs after 135-s were not significantly different from the final power output. In addition, Medbø et al. [24] found that the treadmill analog of AWC for cycle ergometry called the Anaerobic Running Capacity (ARC), was equal to the maximal accumulated oxygen deficit (oxygen deficit $=$ the difference between oxygen demand and oxygen uptake) during exhaustive running for 2-min at supramaximal intensities. Thus, Medbø et al. [24] suggested that anaerobic stores were exhausted and, therefore, ARC would not change significantly after 2 -min of an all-out test. The current findings indicated that there were no significant differences between the estimated $\mathrm{CP}_{150}$ and $\mathrm{AWC}_{150}$ and the criterion $\mathrm{CP}_{180}$ and $\mathrm{AWC}_{180}$ values, respectively. These non-significant differences were evaluated as 30-s averages beginning at 2-min and, thus, supported the findings of Burnley et al. [12] and Medbø et al. [24]. Therefore, the results of the present study indicated that the 3-min all-out test could be shortened to 2.5 - $\mathrm{min}$ without affecting the estimated values for CP and AWC. Reducing the length of the test by 30 -s, results in a less strenuous protocol to estimate CP and AWC.

The results of the validation analyses in the present study provided additional support for shortening the all-out test from 3 to $2.5-\mathrm{min}$. For example, the power output at $\mathrm{CP}_{150}$ was only $2.7 \%(\mathrm{CE}=-5 \mathrm{~W})$ greater than the power output at $\mathrm{CP}_{180}$ and the $\mathrm{AWC}_{150}$ value was $6.9 \%$ $(\mathrm{CE}=0.7 \mathrm{~kJ})$ lower than the $\mathrm{AWC}_{180}$ value. In addition, there were high correlations between $\mathrm{CP}_{150}$ and $\mathrm{CP}_{180}(\mathrm{r}=0.98)$, as well as $\mathrm{AWC}_{150}$ and $\mathrm{AWC}_{180}(\mathrm{r}=0.93)$. Furthermore, the SD values for $\mathrm{CP}_{150}$ and $\mathrm{AWC}_{150}$ (51W and $3.3 \mathrm{~kJ}$, respectively) were $4 \mathrm{~W}$ greater and $0.1 \mathrm{~kJ}$ less than the $\mathrm{SD}$ values for $\mathrm{CP}_{180}$ and $\mathrm{AWC}_{180}$ (47 W and $3.4 \mathrm{~kJ}$, respectively). Thus, these findings indicated that there were close agreements between the estimated and criterion CP and AWC values.

The SEE for $\mathrm{CP}_{150}$ and $\mathrm{AWC}_{150}$ were $4.8 \%$ and $11.8 \%$ of the mean $\mathrm{CP}_{180}$ and $\mathrm{AWC}_{180}$, respectively. The $\mathrm{TE}$ for $\mathrm{CP}_{150}$ and $\mathrm{AWC}_{150}$ were $5.5 \%$ and $13.7 \%$ of the mean $\mathrm{CP}_{180}$ and $\mathrm{AWC}_{180}$, respectively. The differences between the estimated and criterion SEE and TE values were $1 \mathrm{~W}$ and $0.2 \mathrm{~kJ}$ for $\mathrm{CP}$ and AWC, respectively. In the present study, the close similarity between the SEE and TE was due, primarily, to the small CE values. 
Bland and Altman plots [27] were used to describe the distributions of the $\mathrm{CE}$ versus criterion $\left(\mathrm{CP}_{180}\right.$ and $\left.\mathrm{AWC}_{180}\right)$ values (Figures 2 and 3 ). Figures 2 and 3 indicated that the $\mathrm{CE}$ values remained stable across the criterion measures. Furthermore, the correlation coefficients ( $r$ ) for the $\mathrm{CE}$ values versus $\mathrm{CP}_{180}$ and $\mathrm{AWC}_{180}$ were not significantly different from zero at $r=-0.24$ and $r=0.27$, respectively. Thus, the current findings indicated that the magnitude of the $\mathrm{CE}$ values were not affected by the subject's levels of CP or AWC.

\section{Conclusions}

The 3-min all-out test has been proposed as a less time consuming alternative to the original multiple exhaustive workbout model of Moritani et al. [2] for estimating CP and AWC. The demanding nature of this test, however, limits its practicality. Thus, we examined the accuracy of CP and AWC estimates from shorter test durations. The results of the present study showed that there were no significant mean differences and close agreements between $\mathrm{CP}_{150}$ and $\mathrm{CP}_{180}$, as well as

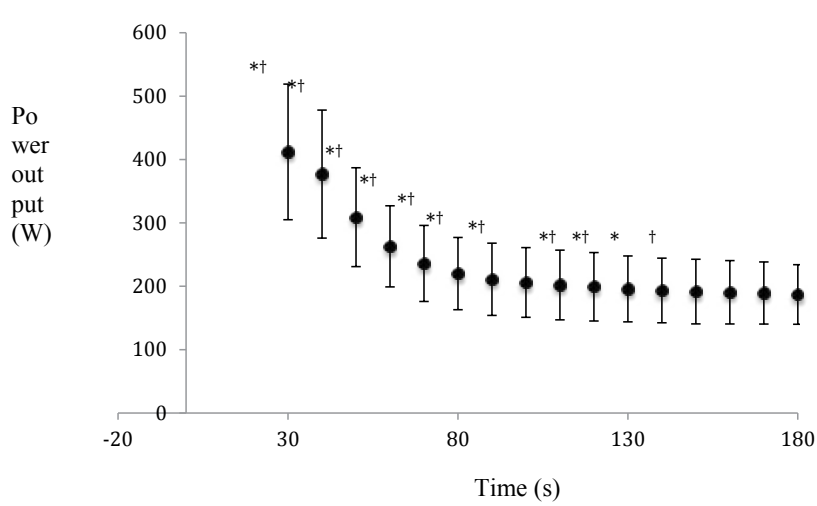

Figure 1: Mean $( \pm S D) 30$-s averaged power outputs for all subjects $(n=28)$ during the 3-min all-out critical power (CP) test. The error bars indicate standard deviations. The asterisks indicate a significant difference in $\mathrm{CP}$ estimates from the criterion $\left(\mathrm{CP}_{180}\right)$ and the crosses $(\dagger)$ indicate a significant difference in anaerobic work capacity (AWC) estimates from the criterion $\left(A W C_{180}\right)$. The results indicated that 150-s was the shortest test duration that resulted in nonsignificant differences between the criterion $\left(\mathrm{CP}_{180}\right.$ and $\left.A W C_{180}\right)$ and estimated $\mathrm{CP}\left(\mathrm{CP}_{150}\right)$ and $\mathrm{AWC}\left(\mathrm{AWC}_{150}\right)$ values.

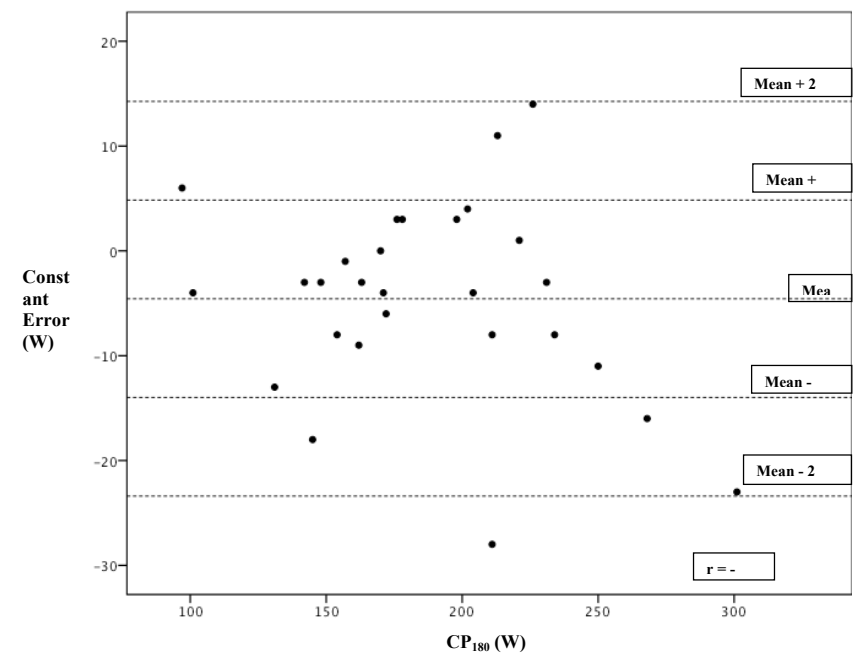

Figure 2: The relationship $(n=28)$ between constant errorr $(C E)$ and the criterion critical power $\left(\mathrm{CP}_{180}\right)$ values.

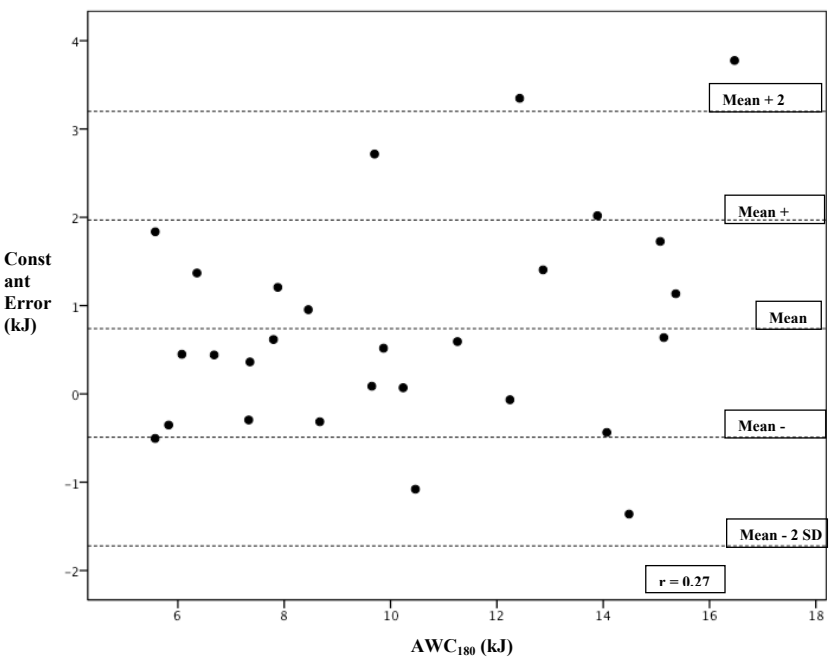

Figure 3: The relationship $(n=28)$ between constant errorr $(C E)$ and the criterion anaerobic work capacity $\left(\mathrm{AWC}_{180}\right)$ values.

between $\mathrm{AWC}_{150}$ and $\mathrm{AWC}_{180}$. Therefore, the current findings indicated that estimates of $\mathrm{CP}$ and AWC were not affected by shortening the test by 30 -s. Reducing the length of the test provides a less strenuous, yet valid protocol for estimating CP and AWC. Future studies should examine the metabolic responses and times to exhaustion at $\mathrm{CP}$ determined from the 2.5-min all-out test and validate the 2.5 -min protocol against other fatigue thresholds.

\section{References}

1. Monod H, Scherrer J (1965) The work capacity of a synergic muscular group. Ergonomics 8: 329-338.

2. Moritani T, Nagata A, deVries HA, Muro M (1981) Critical power as measure of physical work capacity and anaerobic threshold. Ergonomics 24: 339-350.

3. Poole DC, Ward AW, Gardner GW, Whipp BJ (1988) Metabolic and respiratory profile of the upper limit for prolonged exercise in man. Ergonomics 31: 12651279

4. Brickley G, Doust J, Williams CA (2002) Physiological responses during exercise to exhaustion at critical power. Eur J Appl Physiol 88: 146-151.

5. Francis JT, Quinn TJ, Amann M, LaRoche DP (2010) Defining intensity domains from the end power of a 3-min all-out cycling test. Med Sci Sports Exerc 42: 1769-1775.

6. Jenkins DG, Quigley BM (1990) Blood lactate in trained cyclists during ergometry at critical power. Eur J Appl Physiol Occup Physiol 61: 278-283.

7. Hill DW, Smith JC (1999) Determination of critical power by pulmonary gas exchange. Can J Appl Physiol 24: 74-86.

8. Housh DJ, Housh TJ, Bauge SM (1989) The accuracy of the critical powe test for predicting time to exhaustion during cycle ergometery. Ergonomics 32 997-1004.

9. McClave SA, LeBlanc M, Hawkins SA (2011) Sustainablility of critical powe determined by a 3-minute all-out test in elite cyclists. J Strength Cond Res 25 3093-3098.

10. Housh DJ, Housh TJ, Bauge SM (1990) A methodological consideration for the determination of critical power and anaerobic work capacity. Res $Q$ Exercise Sport 61: 406-409

11. Housh TJ, deVries HA, Housh DJ, Tichy MW, Smyth KD, et al. (1991) The relationship between critical power and the onset of blood lactate accumulation J Sports Med Phys Fit 31: 31-36.

12. Burnley, M, Doust JH, Vanhatalo A (2006) A 3-min all-out test to determine peak oxygen uptake and the maximal steady state. Med Sci Sports Exerc 38 1995-2003. 
Citation: Bergstrom HC, Housh TJ, Zuniga JM, Camic CL, Traylor DA, et al. (2012) Estimates of Critical Power and Anaerobic Work Capacity from a Single, All-Out Test of Less than 3-Min. J Sports Med Doping Stud 2:107. doi:10.4172/2161-0673.1000107

13. Vanhatalo A, Jones AM (2008) Influence of prior sprint exercise on the parameters of the 'all-out critical power test' in men. Exp Physiol 94: 255-263.

14. Neder JA, Jones PW, Nery LE, Whipp BJ (2000) Determinants of the exercise endurance capacity in patients with chronic obstructive pulmonary disease: The power-duration relationship. Am J Respir Crit Care Med 162: 497-504.

15. Eckerson JM, Stout JR, Moore GA, Stone NJ, Nishimura K, et al. (2004) Effect of two and five days of creatine loading on anaerobic working capacity in women. J Strength Cond Res 18: 168-173.

16. Eckerson JM, Stout JR, Moore GA, Stone NJ, Iwan KA, et al. (2005) Effect of creatine phosphate supplementation on anaerobic working capacity and body weight after two and six days of loading in men and women. J Strength Cond Res 19: 756- 763.

17. Kendall KL, Smith AE, Graef JL, Fukuda DH, Moon JR, et al. (2009) Effects of four weeks of high intensity interval training and creatine supplementation on critical power and anaerobic working capacity in college-aged men. J Strength Cond Res 23: 1663-1669.

18. Stout JR, Eckerson JM, Housh TJ, Ebersole KT (1999) The effects of creatine supplementation on anaerobic working capacity. J Strength Cond Res 13: 135138.

19. Vanhatalo A, Jones AM (2009) Influence of creatine supplementation on the parameters of the all-out critical power test. J Exerc Sci Fit 7: 9-17.
20. Jones AM, Wilkerson DP, DiMenna F, Fulford J, Poole DC (2007) Muscle metabolic responses to exercise above and below the "critical power" assessed using 31P-MRS. Am J Physiol Regul Integr Comp Physiol 294: R585-593.

21. Vanhatalo A, Doust DH, Burnley M (2007) Determination of critical power using a 3-min all-out cycling test. Med Sci Sports Exerc 39: 548-555.

22. Thompson WR, Gordon NF, Pescatello LS (2010) American College of Sports Medicine: ACSM's guidelines for exercise testing and prescription $\left(8^{\text {th }}\right.$ ed) Lippincott Williams Wilkins, Philadelphia PA.

23. Bergstrom HC, Housh TJ, Zuniga JM, Camic CL, Traylor DA, et al. (2012) A new single work bout test to estimate critical power and anaerobic work capacity. J Strength Cond Res 3: 656-663.

24. Medbø JI, Mohn AC, Tabata I, Bahr R, Vaage O, et al. (1988) Anaerobic capacity determined by maximal accumulated $\mathrm{O}_{2}$ deficit. J Appl Physiol 64 50-60.

25. Day JR, Rossiter HB, Coats EM, Skasick A, Whipp BJ (2003) The maximally attainable $\mathrm{VO}_{2}$ during exercise in humans: The peak vs. maximum issue. J Appl Physiol 95: 1901-1907.

26. Beaver WL, Wasserman K, Whipp BJ (1986) A new method for detecting anaerobic threshold by gas exchange. J Appl Physiol 60: 2020-2027.

27. Bland JM, Altman DG (1986) Statistical methods for assessing agreement between two methods of clinical measurement. Lancet 1: 307-310. 